\title{
VALIDATING ISLAMIC FINANCIAL LITERACY INSTRUMENTS AMONG MUM GENERATION: RASCH ANALYSIS APPROACH
}

\author{
Purnomo M Antara* \\ Universiti Teknologi MARA Malaysia \\ Rosidah Musa \\ Universiti Teknologi MARA Malaysia
}

\begin{abstract}
Islamic financial literacy is an emerging term which is increasingly used in research and policy. Though a study in this area is growing, there is a lack of an accepted method to measure Islamic financial literacy. This study aims to develop a valid and reliable instrument to access Islamic financial literacy among MUM (Muslim Urban Millennial) generations using Rasch analysis. A comprehensive literature review and a qualitative study were initially performed to identify the construct of Islamic financial literacy. A total of 109 respondents from MUM generation completed the 18-item instrument with multiple-choice questions. However, only 85 final sample out of 109 data measured after eliminating the person with the extreme score. The dimensionality of the items was evaluated using WINSTEPS 3.73. Results show that the measurements model is highly reliable with a reliability alpha of 0.87 and 0.96 for person and item, respectively. There is also six misfit item that needs to be reviewed or removed. Differential Item Functioning (DIF) analysis shows that three items have a bias between gender. Overall, the developed Islamic financial literacy scale is a valid and reliable instrument to measure Islamic financial literacy in MUM generation. This measure lays a solid empirical and theoretical foundation for future research in Islamic financial literacy among the MUM generation.
\end{abstract}

Keywords: Islamic financial literacy, Halal, MUM generation, Rasch Analysis.

Received: 9 July 2019

Accepted: 11 September 2020

\section{INTRODUCTION}

The emerging of the Islamic finance industry not only takes places in a majority Muslim country but also starting to enter Western markets and complement conventional financing (Sergie, 2014; Shabbir, Rehman, \& Akhtar, 2016). With an annual growth rate of $20 \%$, it starts to grow across the globe. In the United Kingdom, the government issue around \$327million of Islamic bond (Sukuk). The increasing number of established Islamic Bank around the world show that Islamic finance product can be complementary for conventional banking products. Malaysia, which known as a Halal-hub, is not left behind in promoting Islamic finance industry. With more than $60 \%$ of

*Corresponding author: Purnomo M Antara, Institute of Business Excellence (IBE), Faculty of Business Management, Universiti Teknologi MARA (UiTM), 40450 Shah Alam, Selangor Darul Ehsan. 017-3407225, purnomomantara@gmail.com 
the Muslim population in Malaysia, the Islamic finance industry in Malaysia is a dynamic industry, with $20 \%$ of the Islamic banking market share of the total banking sector. We can see the emerging trends of halal travel, media, food and fashion in Malaysia, especially among Muslim Urban Millennials (MUM). However, the in-depth interview suggests that Muslim millennial does not care about their financing, whether it is Islamic or conventional-based product. We can speculate that the Millennials may have lack knowledge and awareness on Islamic financing products. The level of literacy on Islamic finance may lead to the behaviour of not using Islamic financing products.

\section{LITERATURE REVIEW}

\subsection{Islamic Financial Literacy}

Islamic financial literacy is now becoming a popular research strand among scholars, marketers and policymaker. The concept of financial literacy has been studied by several researchers (Arofah, Purwaningsih, \& Indriayu, 2018; Xiao, Ahn, Serido, \& Shim, 2014). These scholars demonstrate that financial literacy could influence consumer decision in choosing a financial product. Financial literacy was defined by Bhabha, Khan, Qureshi, Naeem, and Khan (2014) as a mishmash of awareness, knowledge, skill, attitude and behaviour essential to make sound financial decisions and also finally achieve individual financial wellbeing. Each person has a different level of literacy, especially in financial. The differences among person may lead to a different action in choosing financial products. However, there is still a lack of study that focuses on Islamic financial literacy. Although the study on Islamic finance is growing, there is a dearth of an accepted method to measure Islamic financial literacy. Thus, against this backdrop, this study aims to develop a reliable and valid of the Islamic Financial Literacy (IFL) instruments. Antara, Musa, and Hassan (2017), defined Islamic financial literacy as the degree to which individuals have a set of knowledge, awareness, and skill to understand the fundamental of Islamic financial information and services that affect its attitude to make appropriate Islamic financing decisions. The study by Antara et al., (2017) focusing on Small Medium Enterprises (SME) that contributed 29.6\% of GDP in Malaysia. However, this study focuses on developing reliable and valid Islamic Financial Literacy measurement scale among Muslim Urban Millennials. It is also essential to focus on Millennials, especially for Muslim Urban Millennials. According to Moreno, Lafuente, Carreon, and Moreno (2017), Millennials formed a large population and becoming an attractive target for many marketers and financial services companies.

\subsection{Rasch Model}

Georg Rasch introduced the Rasch model in 1960. Rasch model addressed several of the limitations of the classical test theory method (Rasch, 1960). In classical test theory, questionnaires developed by giving equal weight to each item. It assumes that each item contributes equally or have the same difficulty to the overall assessment of the latent trait. Besides, the classical theory also stated that intervals between response options for each item are uniform (Baghaei, 2011).

On the other hand, the Rasch model analysis can inform the researcher about the person and item reliability, item and person separation, as well as Cronbach's alpha value (Saidi \& Siew, 2019). Rasch model analysis provides a method to appropriately weight responses of each item and rescale 
an instrument to a linear interval-scored instrument by exploring the probability of individual subjects and difficulty of each item on the instrument being used. In Rasch analysis, the subject's ability to endorse an item and the item's difficulty is measured on the same scale and expressed as a logit value. Rasch analysis widely used in the assessment of the psychometric properties of newly developed instruments. It is used during early development and validation of any new instruments. In this paper, Rasch analysis has been used to modify and improve Islamic Financial Literacy instruments.

\section{METHODOLOGY}

In order to identify the scale items relevant to Islamic financial literacy (IFL), a comprehensive literature search conducted. Several items were adopted from the principal of Islamic finance concepts and Bank Negara Malaysia guidelines (Antara et al., 2017). This study categories Islamic financial literacy into two types; basic literacy and advanced literacy, as suggested by Lusardi (2008). The redundant items eliminated, and 18 items remained and used as a final instrument for this study. Islamic financial literacy in this study uses multiple-choice test-based questions. Table 1 shows the construct and their respective test items. Then, for qualitative content validity, a panel of two experts examined the initial questionnaire. Items were modified based on expert's comments. Content validity and expert panel review led to no changes to the 18 items. Subsequently, to confirm face validity of the scale, 10 MUM generations aged 19-38 years, similar to the target group, were recruited through purposive sampling. The respondents were interviewed to assess each item for ambiguity and complexity.

Table 1: IFL Construct and Respective Items

\begin{tabular}{ccc}
\hline \hline Construct & Code of Item & Items \\
\hline Basic Concepts & IFL01 & Prohibition of Riba \\
& IFL02 & Prohibition of Gharar \\
& IFL03 & Prohibition of Maysir \\
\hline Advanced Concepts: & & Mudarabah \\
Borrowing Concepts & IFL04 & Musyarakah \\
& IFL05 & Ijarah \\
& IFL06 & Murabahah \\
& IFL07 & Istisna \\
& IFL08 & Qard al Hassan \\
& IFL09 & Rahn \\
& IFL10 & Ujrah \\
& IFL11 & Wadi'ah \\
Saving / Investment Concepts & Waqf 01 \\
& IFL12 & Waqf 02 \\
& IFL13 & Zakah \\
& IFL14 & Takaful Return \\
& IFL15 & Takaful Risk \\
& & Takaful Term \\
\hline \hline
\end{tabular}


A total of 109 respondents among MUM generation participated in this study. Rasch Model approach was employed in this study. Rasch analysis can be informative with small samples since the data are responses to individual items (Rasch, 1960; Smith, Lawless, Curda, \& Curda, 1999). The questionnaire employed multiple-choice questions. Since it will only have one correct answer, the results of the test then scored using (1) for the correct answer and (0) for an incorrect answer. This dichotomous data then was analysed using a Rasch based analysis program, Winsteps version 3.73. Rasch analysis introduced by Georg Rasch in 1960 and widely used in the assessment of the psychometric properties of newly developed instruments (Rossi Ferrario, Panzeri, Anselmi, \& Vidotto, 2019). The Rasch Model analysis is a psychometric model used to analyse categorical data as a function of the trade-off between the respondents and the item difficulty (Rasch, 1960). This model can be used not only in educational research but also in other areas, including market research because of their general applicability. The usage of the Rasch measurement model in this study is to assess the MUM Generation literacy measurements on Islamic finance as it gives a more significant analysis of the data. It also allows for better inference to be made, as recommended by Azrilah, Mohd Saidfudin, Faridah, Mohd Zaidi, and Azami, (2013). It is crucial to measure the MUM Generation ability on Islamic financial literacy based on the portion of correct responses and give a depth understanding of each respondent in towards every item difficulty. Salehuddin (2010), in his study on Halal Literacy, classified the questions based on difficulties. It is important to know which questions are valuable in determining the literacy level among respondents. This measurement model will give a picture that respondent with high literacy will be able to answer most of the questions correctly. Whilst, the less literacy respondent, may have difficulties in answering the difficult questions.

\section{RESULTS AND DISCUSSION}

\subsection{Profile of Respondents}

Table 2 shows the demographic profile of respondents for this study. The male respondents were 48 respondents $(44 \%)$, whereas females were 61 respondents $(56 \%)$. However, from the initial results of the Rasch analysis, 24 data were excluded in the analysis because of the existence of extreme score. The extreme score is the highest and lowest possible score for persons on items or for items on persons. In these cases, ten respondents answer correctly for all items, while 14 respondents wrongly answer all items. The data of extreme score eliminated because they do not have an exact measure under Rasch model conditions. After eliminating the extreme score, the final sample was 85 respondents, with 35 respondents $(41.18 \%)$ were male, and 50 respondents $(58.82 \%)$ were female. 
Table 2: Respondent's Profile

\begin{tabular}{|c|c|c|}
\hline & \multicolumn{2}{|c|}{ Gender } \\
\hline & Frequency (n) & Percent (\%) \\
\hline Male & 48 & 44.0 \\
\hline Extreme score & 13 & \\
\hline Non-Extreme score & 35 & \\
\hline Female & 61 & 56.0 \\
\hline Extreme Score & 11 & \\
\hline Non-Extreme Score & 50 & \\
\hline Total & 109 & 100.0 \\
\hline
\end{tabular}

\subsection{Reliability}

The data was analysed using Winsteps version 3.73 to determine the validity and reliability of Islamic Financial Literacy (IFL). Table 4 shows the summary statistics for respondents for Islamic financial literacy. The Cronbach-alpha value was acceptable with a value of 0.94. Cronbach-alpha value implies that the data are more likely to be latent variable if the value is closer to 1 than 0 . However, this Cronbach-alpha value does not show if there is a problem with a person or item. In Rasch analysis, it allows more investigation of the data. According to Bond and Fox (2007), Rasch Analysis enables to check the reliability of the person or item. Table 4 shows that the reliability value for a person is 0.87 , while Table 5 shows the reliability value of items which is 0.96 indicated highly reliable data. The reliability value of more than 0.8 is acceptable (Bond \& Fox, 2007). It is mean that the data could be used for further analysis. The high person reliability indicated that the sample range of the respondents' ability is high (Linacre, 2011). While the mean value for the person is -0.48 shows that the test is found to be a bit difficult for the respondents. Their ability measure, in general, is lower than the mean item measure at +0.00 logit, indicating that these items are more difficult and the chance of correct answer for respondents is low (Wright \& Stone, 1979). Table 4 also shows the person separation is 2.56 . It means there were nearly three groups of respondents for this study. While for items reliability, Table 5 shows there are five groups of items can be formed from the analysis.

Table 4: Person Reliability

\begin{tabular}{lrrrrrrr}
\hline \hline Person & \multicolumn{2}{c}{ Input: 109 } & \multicolumn{2}{c}{ Measure: 85 } & \multicolumn{2}{c}{ INFIT } & \multicolumn{2}{c}{ OUTFIT } \\
& Score & Count & Measure & MNSQ & ZSTD & MNSQ & ZSTD \\
\hline Mean & 8.0 & 18.0 & -0.48 & 0.80 & -0.4 & 1.40 & 0.2 \\
S.D & 5.7 & 0 & 2.58 & 0.79 & 1.3 & 2.62 & 1.5 \\
Max & 17.0 & 18.0 & 3.77 & 4.91 & 3.4 & 9.90 & 5.1 \\
Min & 1.0 & 18.0 & -5.04 & 0.17 & -1.5 & 0.08 & -0.7 \\
Person Separation: $\mathbf{2 . 5 6}$ & & & Reliability: 0.87 & & & \\
Cronbach Alpha Reliability: $\mathbf{0 . 9 4}$ & & & & & \\
\hline \hline
\end{tabular}


TABLE 5: Item Reliability

\begin{tabular}{lrrrrrrr}
\hline \hline Item & & Input: 18 & \multicolumn{2}{c}{ INFIT } & \multicolumn{2}{c}{ OUTFIT } \\
& Score & Count & Measure & MNSQ & ZSTD & MNSQ & ZSTD \\
\hline Mean & 37.9 & 85.0 & 0.0 & 0.91 & -0.5 & 1.89 & 0.0 \\
S.D & 17.6 & 0.0 & 2.05 & 0.49 & 2.6 & 2.43 & 2.0 \\
Max & 80.0 & 85.0 & 2.15 & 1.84 & 4.6 & 8.19 & 3.6 \\
Min & 20.0 & 85.0 & -5.08 & 0.38 & -3.2 & 0.19 & -2.8 \\
Person Separation: 5.09 & & \multicolumn{3}{c}{ Reliability: 0.96 } \\
\hline \hline
\end{tabular}

\subsection{Uni-Dimensionality}

As for the uni-dimensionality assessment, a Principal Component Analysis needs to be performed. This study measured by 18 items scale of Islamic financial literacy. Table 6 shows the amount of the variance explained by different components in the data was $66.2 \%$ which is more than the minimum point of $40 \%$ required by the Rasch Model (Andrich, 1988). 44.0\% was explained by persons, while $22.2 \%$ explained by items. This information explains that the Islamic financial literacy scale has met uni-dimensionality.

Table 6: Standardised Residuals of the scale

\begin{tabular}{|c|c|c|c|c|}
\hline & \multicolumn{3}{|c|}{ Empirical (Observed) } & Modelled (Expected) \\
\hline Total variance in observations & 53.2 & $100.0 \%$ & & $100.0 \%$ \\
\hline Variance explained by measures & 35.2 & $66.2 \%$ & & $63.0 \%$ \\
\hline Variance explained by persons & 23.4 & $44.0 \%$ & & $41.9 \%$ \\
\hline Variance explained by items & 11.8 & $22.2 \%$ & & $21.2 \%$ \\
\hline Unexplained variance (Total) & 18.0 & $33.8 \%$ & $100.0 \%$ & $37.0 \%$ \\
\hline Unexplained variance in $1^{\text {st }}$ contrast & 4.1 & $7.7 \%$ & $22.8 \%$ & \\
\hline
\end{tabular}

\subsection{Construct Validity}

Table 7 shows the item misfit order that shows the items polarity. It used to check the validity of each instrument used for Islamic financial literacy. As shown in Table 7, the analysis involves 18 items of IFL. All items show the positive value of Point Measure Correlation (PMC). To meet the Rasch Model requirement, the Point Measure Correlation (PMC) should have a positive value (Bond \& Fox, 2007). It shows there are no conflicts between items and constructs measured.

Then, by looking at the Mean Square value of Outfit, six items (IFL17, IFL16, IFL18, IFL01, IFL02, and IFL03) shows the high value of Mean Square. High Outfit means square may cause by a few random responses by low performers. The problem needs further review before deciding to remove or not the items from the analysis. In term of difficulties of the items/questions, item IFL17 is the most difficult with logit +2.15 , and the least difficult question is IFL01 with logit -5.08 . We can see that IFL01, IFL02 and IFL03 have low difficulty. All those three items (IFL01, IFL02, \& IFL03) grouped on a construct of basic Islamic financial literacy concept. 
Table 7: Item Misfit

\begin{tabular}{lcccccccc}
\hline \hline Item & \multirow{2}{*}{$\begin{array}{c}\text { Total } \\
\text { Score }\end{array}$} & $\begin{array}{c}\text { Total } \\
\text { Count }\end{array}$ & Measure & $\begin{array}{c}\text { MNS } \\
\text { Q }\end{array}$ & ZSTD & MNSQ & ZSTD & $\begin{array}{c}\text { MEASURE } \\
\text { CORR. }\end{array}$ \\
\hline IFL17 & 20 & 85 & 2.15 & 1.84 & 4.6 & 4.16 & 2.3 & 0.37 \\
IFL04 & 22 & 85 & 1.91 & 0.98 & -0.1 & 0.52 & -0.4 & 0.52 \\
IFL14 & 24 & 85 & 1.67 & 0.57 & -2.9 & 0.27 & -1.1 & 0.46 \\
IFL16 & 24 & 85 & 1.67 & 1.71 & 3.5 & 2.39 & 1.6 & 0.27 \\
IFL18 & 23 & 85 & 1.79 & 1.84 & 4.1 & 2.72 & 1.8 & 0.51 \\
IFL06 & 28 & 85 & 1.18 & 0.74 & -1.4 & 0.39 & -1.1 & 0.39 \\
IFL11 & 29 & 85 & 1.06 & 0.50 & -3.0 & 0.24 & -1.7 & 0.24 \\
IFL05 & 31 & 85 & 0.80 & 0.63 & -1.9 & 0.37 & -1.3 & 0.37 \\
IFL10 & 33 & 85 & 0.54 & 0.45 & -3.0 & 0.23 & -2.1 & 0.23 \\
IFL07 & 34 & 85 & 0.41 & 0.70 & -1.3 & 0.45 & -1.3 & 0.45 \\
IFL08 & 34 & 85 & 0.41 & 0.67 & -1.5 & 0.63 & -0.7 & 0.63 \\
IFL09 & 35 & 85 & 0.28 & 0.55 & -2.1 & 0.62 & -0.8 & 0.62 \\
IFL12 & 38 & 85 & -0.12 & 0.38 & -3.2 & 0.19 & -2.8 & 0.19 \\
IFL13 & 41 & 85 & -0.51 & 0.44 & -2.8 & 0.40 & -1.7 & 0.4 \\
IFL15 & 42 & 85 & -0.64 & 0.46 & -2.8 & 0.44 & -1.5 & 0.44 \\
IFL03 & 71 & 85 & -3.65 & 1.33 & 2.0 & 8.19 & 3.6 & 0.23 \\
IFL02 & 73 & 85 & -3.89 & 1.28 & 1.4 & 6.32 & 3.1 & 0.23 \\
IFL01 & 80 & 85 & -5.08 & 1.31 & 0.9 & 5.57 & 3.3 & 0.09 \\
\hline \hline
\end{tabular}

\subsection{Differential Item Functioning (DIF)}

According to Aryadoust, Goh, and Kim (2011), Differential Item Functioning in the Rasch Model can be used to looks at psychometric differences for item functions as a group compared to others. Items may be biased for a particular group of respondents based on certain factors such as gender, ethnicity, education background and others where several items may bias for subsamples. Table 8 shows the summary of Rasch measurement for gender. Several items were biased to the subsamples. It can be shown by looking at the probability value below 5\% (0.05). Table 8 shows that the bias items between male and female are IFL03, IFL16 and IFL18. It indicates that gender influenced the response to those three items. Overall, most of the items do not have different responses between male and female.

Table 8: Plot of Item Estimates between Gender from Differential Item Functioning Analysis.

\begin{tabular}{ccccc}
\hline \hline $\begin{array}{c}\text { Person } \\
\text { CLASSES }\end{array}$ & $\begin{array}{c}\text { SUMMARY DIF } \\
\text { CHI-SQUARE }\end{array}$ & D.F. & PROB. & Item \\
\hline 2 & 0.8888 & 1 & 0.3458 & IFL01 \\
2 & 1.8912 & 1 & 0.1691 & IFL02 \\
2 & 7.1561 & 1 & 0.0075 & IFL03 \\
2 & 0.0527 & 1 & 0.8185 & IFL04 \\
2 & 0.0835 & 1 & 0.7726 & IFL05 \\
2 & 0.1392 & 1 & 0.7091 & IFL06 \\
2 & 1.8931 & 1 & 0.1688 & IFL07 \\
2 & 1.8931 & 1 & 0.1688 & IFL08 \\
2 & 0.1155 & 1 & 0.7339 & IFL09 \\
2 & 0.0000 & 1 & 1.0000 & IFL10 \\
2 & 0.8886 & 1 & 0.3459 &
\end{tabular}




\begin{tabular}{ccccc}
\hline \hline $\begin{array}{c}\text { Person } \\
\text { CLASSES }\end{array}$ & $\begin{array}{c}\text { SUMMARY DIF } \\
\text { CHI-SQUARE }\end{array}$ & D.F. & PROB. & Item \\
\hline 2 & 0.1394 & 1 & 0.7089 & IFL12 \\
2 & 3.6272 & 1 & 0.0568 & IFL13 \\
2 & 0.2784 & 1 & 0.5977 & IFL14 \\
2 & 1.9705 & 1 & 0.1604 & IFL15 \\
2 & 5.7128 & 1 & 0.0168 & IFL16 \\
2 & 2.3038 & 1 & 0.1291 & IFL17 \\
2 & 4.7101 & 1 & 0.0300 & IFL18 \\
\hline \hline
\end{tabular}

\section{CONCLUSION}

Islamic financial literacy scale in this study is a valid and reliable instrument to measure literacy among MUM generation on Islamic finance. This measure lays a solid empirical and theoretical foundation for future research. It also tailored interventions to promote Islamic financial literacy to the MUM generational cohort.

Data collected from 109 respondents and only 85 data measured after eliminating extreme score data. Eighteen items from Islamic financial literacy measurements were measured through the Rasch analysis. All person and item have high reliability for this study, with reliability alpha of 0.87 and 0.96 for person and item respectively. Dimensionality analysis shows that Islamic financial literacy scale achieves the uni-dimensionality test with $66.2 \%$ variance explained by measures. It shows that Islamic financial literacy scale in this study measures what it should measure. In terms of construct validity, six items (IFL17, IFL16, IFL18, IFL01, IFL02, and IFL03) have a high value of mean square. However, all items show a positive value of Point Measure Correlation that indicates the items measure what it should measure. Thus, there are no items that were deleted. Besides, from the Differential Item Functioning (DIF) analysis shows that three items have biased by gender (IFL03, IFL16 and IFL18). The findings also show that most of the respondents can answer the basic concept of Islamic financial literacy questions (IFL01, IFL02 and IFL03) but differ from the other items.

\section{ACKNOWLEDGEMENT}

The authors would like to thank the Ministry of Education of Malaysia (MOE) in providing the Fundamental Research Grant Scheme (FRGS), and Universiti Teknologi MARA (UiTM) especially Institute of Business Excellence (IBE) for assisting this research.

\section{REFERENCES}

Andrich, D. (1988). Rasch Models for Measurement. Beverly Hill: Sage University Paper Series on Quantitative Applications in Social Science.

Antara, P. M., Musa, R., \& Hassan, F. (2017). Conceptualisation and Operationalisation of Islamic Financial Literacy Scale. Pertanika Journal of Social Sciences \& Humanities, 25(S), 251260. 
Arofah, A. A., Purwaningsih, Y., \& Indriayu, M. (2018). Financial Literacy, Materialism and Financial Behavior. International Journal of Multicultural and Multireligious Understanding, 5(4), 370-378.

Aryadoust, V., Goh, C. C. M., \& Kim, L. O. (2011). An Investigation of Differential Item Functioning in the MELAB Listening Test. Language Assessment Quarterly, 8(4), 361-385.

Azrilah, A. A., Mohd Saidfudin, M., Faridah, M. I., Mohd Zaidi, O., \& Azami, Z., (2013). Insights into Engineering Education Learning Outcome's Assessment with Rasch Model. Research Journal of Applied Sciences, Engineering and Technology, 6(19), 3520-3526.

Baghaei, P. (2011). Validation of a Multiple-Choice English Vocabulary Test with the Rasch Model. Journal of Language Teaching and Research, 2(5), 1052-1060.

Bhabha, J. I., Khan, S., Qureshi, Q. A., Naeem, A, \& Khan, I. (2014). Impact of Financial Literacy on Saving-Investment Behavior of Working Women in the Developing Countries. Research Journal of Finance and Accounting, 13(5), 118-122.

Bond, T. G., \& Fox, C. M. (2007). Applying the Rasch Model: Fundamental Measurement in the Human Science ( $2^{\text {nd }}$ ed.). Mahwah, NJ: Lawrence Erlbaum Associates.

Linacre, J. M. (2011). A User's guide to WINSTEPS Ministeps: Rasch-Model Computer Program. Program Manual 3.73.

Lusardi, A. (2008). Financial Literacy: An Essential Tool for Informed Consumer Choice? NBER Working Paper No 14084. Retrieved from http://www.nber.org/papers/w14084.pdf

Moreno, F. M., Lafuente, J. G., Carreon, F. A., \& Moreno, S. M. (2017). The Characterisation of the Millennials and Their Buying Behavior. International Journal of Marketing Studies, 9(5), 135-144.

Rasch, G. (1960). Probabilistic Models for Some Intelligence and Attainment Tests. Copenhagen: Danish Institute for Educational Research.

Rossi Ferrario, S., Panzeri, A., Anselmi, P., \& Vidotto, G. (2019). Development and Psychometric Properties of a Short Form of the Illness Denial Questionnaire. Psychology Research and Behavior Management, 12, 727-739.

Saidi, S. S., \& Siew, N. M. (2019). Reliability and Validity Analysis of Statistical Reasoning Test Survey Instrument using the Rasch Measurement Model. International Electronic Journal of Mathematics Education, 14(3), 535-546.

Salehudin, I. (2010). Halal Literacy. A Concept Exploration and Measurement Validation. ASEAN Marketing Journal, 2(1), 1-12.

Sergie, M. A. (2014). The Rise of Islamic Finance. Council on Foreign Relations. Retrieved from https://www.cfr.org/backgrounder/rise-islamic-finance

Shabbir M. S., Rehman A. K., \& Akhtar T. (2016). The Role of Islamic Leading Organisations for the Promotion of Islamic Finance in Western Countries. Journal of Internet Banking and Commerce, 21, 157

Smith, E. V., Lawless, K. A., Curda, L., \& Curda, S. (1999). Measuring change in efficacy. Popular Measurement, 2(1), 31-33.

Wright, B. D., \& Stone, M. H. (1979). Best Test Design Rasch Measurement. Chicago, IL: Mesa Press.

Xiao, J. J., Ahn, S. Y., Serido, J., \& Shim, S. (2014). Earlier Financial Literacy and Later Financial Behaviour of College Students. International Journal of Consumer Studies, 38(6), 593-601. 